\title{
Tongue Hyperpigmentation Induced by Cyclophosphamide and Doxorubicin: Case Report
}

\author{
Iman $\mathbf{M}^{1,2 *}$ and Essam $\mathrm{MB}^{3}$ \\ ${ }^{1}$ School of Health Sciences, University of KwaZulu-Natal, Durban, South Africa \\ ${ }^{2}$ Senior Oncology Pharmacist, King Abdulaziz Medical City, Al Hasa, Saudi Arabia \\ ${ }^{3}$ Chairman of internal medicine department, Muhammad Dossey Hospital, AL Khobar, Saudi Arabia
}

*Corresponding author: Iman M, King Abdulaziz Medical City, Al Hasa, Saudi Arabia.

To Cite This Article: Iman M, Essam MB. Tongue Hyperpigmentation Induced by Cyclophosphamide and Doxorubicin: Case Report. Am J Biomed Sci \& Res. 2021 - 14(3). AJBSR.MS.ID.001992. DOI: 10.34297/AJBSR.2021.14.001992.

Received: 眥 September 21, 2021; Published: 紫 October 05, 2021

\begin{abstract}
Background

Antineoplastic chemotherapy is associated with many side effects including mucosal and cutaneous manifestations. Nail and mucosal pigmentation are examples of these side effects.

\section{Case presentation}

We present a 46-year-old Saudi female with breast cancer who experienced hyperpigmentation of tongue secondary to doxorubicin and cyclophosphamide used for her disease. Patient complained of painless tongue hyperpigmentation that appeared after second cycle of chemotherapy administration. The tongue had normal texture with no swelling or swallowing difficulties. She was diagnosed with chemotherapy-induced tongue hyperpigmentation and advised with good mouth hygiene and antiseptic mouth wash. The dark lesions were constant in the shape, colour and size until the end of chemotherapy administration. After few months of the end of her chemotherapy treatment, the tongue hyperpigmentation disappeared spontaneously without any treatment.
\end{abstract}

\section{Conclusion}

Hyperpigmentation is a rare case associated with doxorubicin and cyclophosphamide administration. It fades mostly after weeks to few months of cessation of medications. Females especially with dark skin are more susceptible to this side effect. We advise patients with good oral hygiene. Chlorohexidine mouthwash may be used for mild symptoms, and artificial saliva for mouth dryness. In moderate to severe symptoms, patients should be assessed and examined thoroughly for any associated infection or other reasons.

Keywords: Tongue, Typerpigmentation, Cyclophosphamide, Doxorubicin, Chemotherapy

\section{Background}

Tongue hyperpigmentation is a harmless condition mainly occurs on the dorsum of the tongue. Several medications can induce hyperpigmentation of the tongue. According to the American academy of oral medicine, Tongue hyperpigmentation affects $13 \%$ of the world population. It happens due to poor oral hygiene [1]. Bacteria accumulate and build-up keratin on the tongue surface. Tongue hyperpigmentation can also be associated with the use of certain medications such as antibiotics and bismuth. Drinking of coffee or tea for several years as well as smoking also affects [2].
Many reports were recorded as tongue hyperpigmentation induced by chemotherapy.

Capecitabine, doxorubicin, cyclophosphamide, bleomycin, vincristine, fluorouracil, epirubicin, carboplatin, Tegafur, decarbazine, paclitaxel, docetaxel, cisplatin, ifosphamide and temozolamide are the main agents that may cause tongue hyperpigmentation [3-12]. Increased melanin within the lingual mucosa may be the reason for this complication. We describe a 46-year-old Saudi female who was receiving combination 
chemotherapy including doxorubicin and cyclophosphamide for breast cancer and developed tongue hyperpigmentation.

\section{Case presentation}

A 46-year-old Saudi female nonsmoker with brown dark skin has had breast cancer (invasive ductal carcinoma grade 2) in the right side, T3N2M0, STAGE III A, strong positive hormonal receptors values (ER100\%, PR90\%), immunohistochemistry for HERneu2 was negative (IHC $=0$ ), KI67 30\%. Patient received the first dose of chemotherapyin the firstweekofJanuary 2019. Patientadministered dose dense AC (Adriamycin \{doxorubicin\} and cyclophosphamide) protocol (doxorubicin $60 \mathrm{mg} / \mathrm{m}^{2}$ and cyclophosphamide 600 $\mathrm{mg} / \mathrm{m} 2$ every 14 days) as neoadjuvant chemotherapy. Patient complained of painless hyperpigmentation lesions in the tongue that appeared after second cycle of chemotherapy (17 days from first AC administration), (Figure 1). Patient was examined; there were irregular shapes of hyperpigmentation lesions in the apex and dorsum of the tongue, no colored lesions apart from tongue and the tongue had normal texture with no swelling and patient denied any problems with swallowing. Patient had normal lab tests; total bilirubin was normal 5.3umol/L(reference rang 3.4-20.5umol/L) and complete blood count (CBC); hgb $126 \mathrm{gm} / \mathrm{L}$ (reference range 120-160gm/L), RBC 5.17 X1012/L (reference range 4-5.4X1012 /L), hct $0.4 \mathrm{~L} / \mathrm{L}($ reference range0.36-0.540 L/L), MCV $73 \mathrm{fL}$ (reference range76-96 fL), MCH 27pg (reference range 27-32pg) and Iron 7.5umol/L(reference range 4.48-27.92 umol/L), so we excluded hyperpigmentation induced by anemia in this patient.

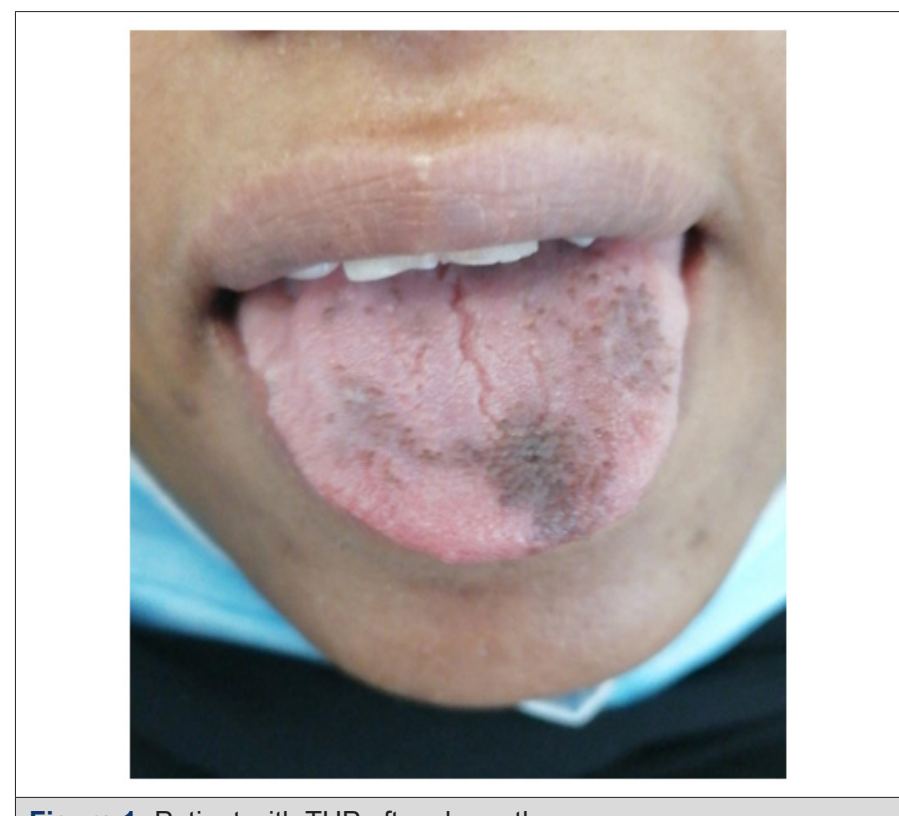

Figure 1: Patient with THP after chemotherapy.
Patient is nonsmoker and she denied extensive use of coffee and tea drinks. Patient had not administered any antibiotics upon the time of THP presentation and no history of any drug reactions in the past. As the hyperpigmentation tongue lesions are not harm and painless, chemotherapy doses continued to be given. The dark lesions remained constant in the shape, size and colour till the end of chemotherapy administration. Patient denied any similar lesions in tongue in the past, but she mentioned that she had some hyperpigmentation in her back without any associated difficulty as a past history. As it is painless with no swelling and no suspected malignancy or disease, we just prescribed for her chlorohexidine mouth wash as germicidal mouthwash that reduces bacteria in the mouth. We advise the patient for good mouth hygiene and brushing of tongue while brushing her teeth. After few months of the end of AC treatment, the tongue hyperpigmentation (THP) disappeared spontaneously without any specific treatment. Doxorubicin and cyclophosphamide course was followed by 4 cycles of docetaxel. Subsequently radiotherapy was given followed by hormone therapy. We followed lup the patient for more than 14 months and she is doing well.

\section{Discussion}

Multiple chemotherapy agents can cause tongue hyperpigmentation (THP) either as single agents or in combination. These agents induce dermatological side effects involving skin, hair, nails and mucous membranes. No accurate numbers are available for the incidence of oral hyperpigmentation induced by chemotherapy. Saraswat et al., screened 153 cancer patients for cutaneous adverse effects induced by chemotherapy. The incidence of oral hyperpigmentation was detected in 4 patients (4\%) administrated capecitabine [13]. Shruthi Acharya et al., studied 52 patients to describe the oral changes as oral mucositis, oral pigmentation with breast cancer patients during and after chemotherapy. They found that oral mucosal pigmentation involved $28.8 \%$ of patients during chemotherapy and increased to $50 \%$ at the end of chemotherapy $(p<0.01)$. This pigmentation was mostly seen on the tongue [14]. Tongue hyperpigmentation is a painless condition. Previous studies have been reported an association between chemotherapeutic drugs and hyperpigmentation (Table 1). According to the American academy of oral medicine, Tongue hyperpigmentation affects $13 \%$ of the world population. It happens due to poor oral hygiene [1]. Bacteria accumulate and build-up keratin on the tongue surface. Tongue hyperpigmentation can also be associated with the use of certain medications such as antibiotics and bismuth. Long time drinking of coffee and tea as well as smoking also affect [2]. Few reports recorded THP induced by chemotherapy (Table 1). 


\begin{tabular}{|c|c|c|c|c|c|c|c|c|c|c|c|}
\hline & Country & Disease & Agents & $\mathbf{G}$ & Age & Skin col & $\begin{array}{c}\text { Coloured } \\
\text { places }\end{array}$ & $\begin{array}{l}\text { Other } \\
\text { places }\end{array}$ & $\begin{array}{c}\text { Start 1st } \\
\text { cycle }\end{array}$ & Disaperance & \\
\hline $\begin{array}{l}\text { Our case } \\
2020\end{array}$ & KSA & $\mathrm{BC}$ & $\mathrm{AC}$ & $\mathrm{F}$ & $46 \mathrm{Y}$ & Dark & $\begin{array}{l}\text { Tip and } \\
\text { dorsum }\end{array}$ & no & 17 days & 6 month & 8 \\
\hline $\begin{array}{c}\text { Blaya\& Saba, } \\
2011 \text { [13] }\end{array}$ & USA & $\mathrm{BC}$ & $\mathrm{AC}$ & $\mathrm{F}$ & $42 \mathrm{Y}$ & Dark & Surface, FP,VP & no & 42days & 12 weeks & \\
\hline $\begin{array}{c}\text { Vasudevan B } \\
2010 \text { [14] }\end{array}$ & India & SA & CAP & M & $59 \mathrm{Y}$ & Dark & FP & $\begin{array}{l}\text { Hands } \\
\text { and feet. }\end{array}$ & 42days & $\begin{array}{l}\text { Resolved } \\
\text { after } \\
\text { complete } \\
\text { treatment }\end{array}$ & \\
\hline $\begin{array}{c}\text { Abbasi \& } \\
\text { Wang, 2008 } \\
{[15]}\end{array}$ & USA & KS & A & M & $39 Y$ & Dark & $\begin{array}{l}\text { Entire dorsal } \\
\text { surface }\end{array}$ & Nails, lips & nk & nk & \\
\hline $\begin{array}{l}\text { Kathleen M., } \\
2013 \text { [16] }\end{array}$ & USA & SM & $\mathrm{P}, \mathrm{I}, \mathrm{T}, \mathrm{V}$ & $\mathrm{F}$ & $16 \mathrm{Y}$ & Dark & $\begin{array}{l}\text { Distal dorsal } \\
\text { tip }\end{array}$ & Nails & 5 days & 18 month & \\
\hline $\begin{array}{c}\text { Krutchik, } \\
\text { Buzdar1979 } \\
\text { [7] }\end{array}$ & & $\mathrm{BC}$ & A & $\mathrm{F}$ & $41 Y$ & Dark & $\mathrm{nk}$ & $\mathrm{nk}$ & nk & nk & \\
\hline \multirow{2}{*}{$\begin{array}{l}\text { Rao, et al., } \\
1976 \text { [17] }\end{array}$} & & ALL & CAP & $\mathrm{F}$ & $19 \mathrm{M}$ & Dark & $\mathrm{nk}$ & $\mathrm{nk}$ & nk & nk & \\
\hline & & WT & CAP & $\mathrm{F}$ & $9 \mathrm{Y}$ & Dark & nk & $\mathrm{nk}$ & nk & $\mathrm{nk}$ & \\
\hline $\begin{array}{l}\text { Guillermo et } \\
\text { al., } 2009 \text { [9] }\end{array}$ & Spain & $\mathrm{BC}$ & CAP & $\mathrm{F}$ & $58 \mathrm{Y}$ & White & Dorsum, FP, & $\begin{array}{c}\text { face, } \\
\text { hands, } \\
\text { palms } \\
\text { soles, and } \\
\text { tongue }\end{array}$ & 84 days & Six month & \\
\hline $\begin{array}{l}\text { Saraswat et } \\
\text { al., } 2019 \text { [1] }\end{array}$ & India & $\begin{array}{c}4 \\
\text { patients }\end{array}$ & CAP & $\mathrm{F}$ & $\mathrm{nk}$ & Dark & $\begin{array}{l}\text { Buccal, labial } \\
\text { OM, palate. FP }\end{array}$ & $\mathrm{nk}$ & $\begin{array}{l}\text { day } 10 \\
\text { and } 30\end{array}$ & $\mathrm{nk}$ & \\
\hline \multirow{5}{*}{$\begin{array}{l}\text { Ranawaka } \\
2018 \text { [18] }\end{array}$} & \multirow{5}{*}{$\begin{array}{c}\text { Sri } \\
\text { Lanka }\end{array}$} & $\mathrm{BC}$ & $\mathrm{A}, \mathrm{C}$ & $\mathrm{F}$ & $41 \mathrm{Y}$ & Dark & Surface & $\begin{array}{l}\text { Nails, } \\
\text { palms, } \\
\text { sols }\end{array}$ & 10 days & & \\
\hline & & $\mathrm{BC}$ & $A, C$ & $\mathrm{~F}$ & $36 \mathrm{Y}$ & Dark & Surface & $\begin{array}{l}\text { Nails, } \\
\text { palms } \\
\text {,sols }\end{array}$ & 18 days & 4-6 months & \\
\hline & & $\mathrm{BC}$ & $\begin{array}{l}\mathrm{FU} \\
\text {,EP,C }\end{array}$ & $\mathrm{F}$ & $48 Y$ & Dark & $\begin{array}{l}\text { Dorsum, tip, } \\
\text { undersurface, } \\
\text { gum, OM, FP }\end{array}$ & Nails & 63 days & & \\
\hline & & $\mathrm{BC}$ & $\begin{array}{l}\mathrm{FU} \\
\text {,EP,C }\end{array}$ & $\mathrm{F}$ & $54 \mathrm{Y}$ & Dark & $\begin{array}{l}\text { Lateral } \\
\text { margins }\end{array}$ & Nails & 46 days & & \\
\hline & & NHL & $\mathrm{A}, \mathrm{V}, \mathrm{C}$ & $\mathrm{F}$ & $37 Y$ & Dark & $\begin{array}{c}\text { Lateral margin, } \\
\text { tip }\end{array}$ & Nails & 20 days & & \\
\hline
\end{tabular}




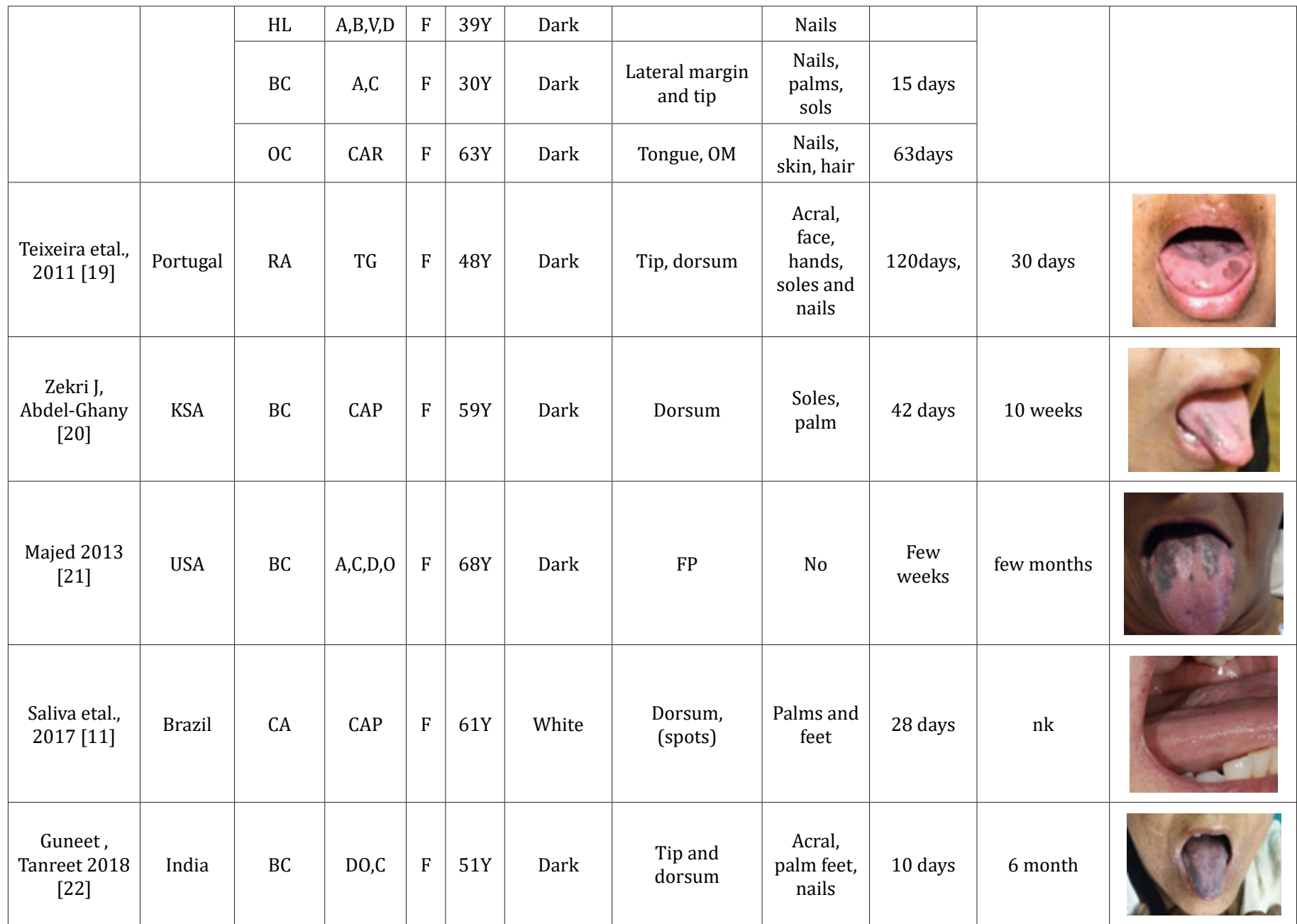

*Note: G: Gender, ALL: Acute lymphocytic leukemia, G: Gender, F: Female, BC : Breast cancer, SA: Stomach adenocarcinoma, KS: Kaposi sarcoma, C: Cyclophosphamide, A: Doxorubicin, CAP: Capecitabiene, V: Vincristien, FU: Fluro uracil, EP: Epirubicin, CAR: Carboplatin, TG: Tegafur, B: Bleomycin, D: Decarbazine, T :Paclitaxel, DO: Docetaxel, P: Cisplatin, I: Ifosphamide, T: Temozolamide, TCD: Total cumulative dose, WT: Wilms' tumor, NHL: NonHodgkin's lymphoma, RA: Rectal adenocarcinoma, OC: Overian carcinoma, HL: Hodgkin's lymphoma, OM: Oral mucosa, SM: Spinal medulloepithelioma, FP: Fillform papillae, VP: Vallate papillae, CA: Colon cancer, Y: Year, M: Month.

The exact pathophysiology for THP is still not well understood. The tongue is covered by tiny bumps papillae. Chemotherapy kills fast growing cells like tongue mucosal cells. The dead cells collect on papillae tips and look longer. These long papillae are easily stained by chemical agents as chemotherapy giving black tongue. This appearance may be related to poor oral hygiene, low saliva production and liquid diet. Poor oral hygiene gives a chance for dead cells to accumulate on the tongue. So, we advise the patient to have regular brushing of her teeth and tongue. Low saliva production is another factor increases hyperpigmentation. Saliva helps in swallowing dead cells induced by chemotherapy. Many tests are used to evaluate the saliva production. Schirmer's test, is most commonly used in clinical practice. Other tests for measuring salivary gland function are either invasive (minor salivary gland biopsy and sialography) or require special equipment (scintigraphy or magnetic resonance scanning) making them unsuitable for use in population based studies [15]. Our patient denied any decrease of saliva production as he denied any sticky saliva or any mouth dryness requiring frequent sips of fluid intake.

Certain chemicals react with acids on the surface of the tongue and turn it black. We studied the acidity nature of doxorubicin and cyclophosphamide to evaluate which drug that may potentiate this action. Cyclophosphamide is a fine white crystalline powder. It is acidic in nature with PH of 4 to 6 [16]. Doxorubicin hydrochloride appears as orange-red thin needles. It is alkaline in nature with PH of 9. So, probably this black colour of tongue is induced by the alkaline doxorubicin. Doxorubicin may chemically react with the acidic surface of the tongue to produce colored lesion but poor hygiene may change the acidic nature of the tongue surface to give chance for cyclophosphamide reaction [17]. Other mechanism, the hyperpigmentation could be secondary to accumulation of drugs in the affected areas by saliva excretion inducing direct cytotoxicity on the melanocytes. 
Other pathophysiology has been suggested by Krutchik about the role of melanocyte-stimulating hormone (MSH) enhancement by doxorubicin which drives to THP [18]. MSH levels are different according to skin photo types of subjects, which may explain why some patients have this side effect and others do not have. MSH enhances tyrosine and cyclic adenosine monophosphate in the melanocytes. High tyrosine levels may enhance more production of melanin [19]. Guillermo has another explanation of THP. He sees that chemotherapy destroys tumor-specific lymphocytes then consequently leads to the flare-up of hyperpigmentation lesions or induction of malignant melanoma after many cycles of chemotherapy. The stress, tension and scary feeling of chemotherapy alter or reduce $\mathrm{T}$ lymphocytes. These changes lead to deregulation of the melanoma growth stimulating activity (MGSA) gene in melanocytes that stimulate the development of melanocytes into normal or atypical nevi [20]. Llistosella et al., proposed a mixed mechanism involving melanocyte hyperplasia and a decreased keratinocyte turnover, as basal pigmentation and dermal melanophages [21].

Fifteen case reports were reviewed including our presented case with total of 26 cases (Table 1). We found that most cases are females (24 cases 92\%) and 2 are males. Most common chemotherapy agents inducing THP were cyclophosphamide, doxorubicin, capecitabine, vincristine, fluorouracil, epirubicin, carboplatin, tegafur, bleomycin, decarbazine, paclitaxel, docetaxel, cisplatin, ifosphamide, and temozolamide. Doxorubicin is the most chemotherapy induced THP (10 reports: $38.5 \%$ ) as a single agent and in combination. Capecitabine was included in 7 reports $27 \%$ as a single agent only. The incidence of THP after chemotherapy is from 5 to 120 days, most patients have dark skin. Most colored area is in tongue dorsum. All patients did not complain of any mouth pain or any discomfort except one patient received capecitabine complained of burning mouth [22]. The symptoms were relieved after applying lanolin-based lip balm and toothpaste without sodium lauryl sulfate [22,23].

\section{Conclusion}

Tongue hyperpigmentation is an adverse event related to doxorubicin and cyclophosphamide. It is mostly appeared without any symptoms and fades substantially after weeks to few months of cessation of medications. Females especially with dark skin are more susceptible to this adverse event. We advise patients with good oral hygiene. Patient with mouth dryness, artificial saliva will be a good management. If mild symptoms appeared, chlorohexidine mouth wash will be enough. In moderate to severe symptoms, patients should be assessed and examined thoroughly for any associated infection or other reasons.

\section{References}

1. https://www.aaom.com/hairy-tongue

2. Cohen PR (2009) Black tongue secondary to bismuth subsalicylate: case report and review of exogenous causes of macular lingual pigmentation. J Drugs Dermatol 8(12): 1132-1135.

3. Blaya M, Saba N (2011) Chemotherapy-induced hyperpigmentation of the tongue. N Engl J Med 365(10).

4. Vasudevan B (2010) An unusual case of capecitabine hyperpigmentation: Is hyperpigmentation a part of hand-foot syndrome or a separate entity. Indian J Pharmacol 42(5): 326-328.

5. Abbasi, Naheed, Wang N (2008) Doxorubicin-induced hyperpigmentation. Dermatolo Online 14(10): 18.

6. Kathleen M, Philip RC (2013) Chemotherapy-Associated Tongue Hyperpigmentation and Blue Lunula. J Drugs Dermatol 12(2):223-226.

7. Rao SP, Potnis AV, Sobrinho TC, Brown AK (1976) Pigmentation of the tongue after treatment with adriamycin. Cancer Treat Rep 60(9):14021404.

8. Ranawaka RR (2009) Patterns of chromonychia during chemotherapy in patients with skin type V Patterns of chromonychia during chemotherapy in patients with skin type $\mathrm{V}$ and outcome after 1 year of follow-up. Clin Exp Dermatol 34(8): 920-926.

9. Teixeira V, Vieira R, Américo F (2011) Tegafur-induced acral hyperpigmentation. Dermatology Reports 3(2): 30.

10.Zekri J, Abdel G (2013) Hyperpigmentation of the tongue, palms and soles: Rare side effect of capecitabine. J Cancer Res Ther 1(10): 226-229.

11. Majed (2013) Tongue hyperpigmentation associated with chemotherapy. J Community Hosp Intern Med Perspect 3(3-4): 21047.

12. Guneet A, Tanreet K (2018) Peculiar Acral and Oral Pigmentation after Docetaxel Therapy: An Unresolved Dilemma. Indian Journal of Drugs in Dermatology 4(1): 26.

13. Saraswat N, Neema S, Sengar K (2019) Pigmentary adverse effects of chemotherapeutic agents. Pigment Int 6(1): 24-28.

14. Acharya S, Pai KM, Bhat S, Mamatha B, Bejadi VM, et al. (2017) Oral changes in patients undergoing chemotherapy for breast cancer. Indian J Dent Res 28(3): 261-268.

15. Cho P, Yap M (1993) Schirmer Test - 11: A clinical study of its repeatability. Optom Vis Sci 70(2): 157-159.

16. Cyclophosphamide @ pubchem.ncbi.nlm.nih.gov [Internet], last accessed in August 2020

17. Doxorubicin-Hydrochloride @ pubchem.ncbi.nlm.nih.gov [Internet], last accessed in August 2020.

18. Krutchik AN, Buzdar AU (1979) Pigmentation of the tongue and mucous membranes associated with cancer chemotherapy. South Med J 72(12): 1615-1616.

19. Willems M, Munte K, Vrolijk JM, Den Hollander JC, Böhm M, et al. (2003) Hyperpigmentation during interferon-alpha therapy for chronic hepatitis C virus infection. Br J Dermatol. 149(2): 390-394.

20. Villalon G, Martín JM, Pinazo MI, Calduch L, Alonso V, et al. (2009) Focal acral hyperpigmentation in a patient undergoing chemotherapy with capecitabine. Am J Clin Dermatol 10(4): 261-263.

21. Llistosella E, Codina A, Alvarez R, Pujol RM, Moragas JM (1991) Tegafurinduced acral hyperpigmentation. Cutis 48(3):205-207. 
22. Silva PVR, Chicrala GM, Soares LAV, Dias RR, Santos PSS (2017) Oral hyperpigmentation as adverse effect to capecitabine. J Oral Diagnosis 2: $1-5$.
23. Santos PS, Tinôco AJE, Souza LM, Ferreira R, Ikoma MRV, et al. (2013) Efficacy of HPA lanolin $\AA$ in treatment of lip alterations related to chemotherapy. J Appl Oral Sci 21(2): 163-166. 